of grants in aid, would be the weakening of the principle of co-operation. The research associations scheme is a scheme based on the conception that in scientific research, no less than in trade, there is a vast area in which the work needed to be done can be done effectively only by co-operation. One of the strongest arguments for such co-operative research is that, by its means, researches of vital importance to the respective industries can be undertaken, though they may be of a nature and extent which would make it impossible for any individual firm to undertake them. It is true that, theoretically, the research associations would still be free to undertake such researches even if Government grants ceased and relations with the Department of Scientific and Industrial Research were severed. In practice, however, there can be little doubt that the loss of the Government grant and the severance of relations with the Department of Scientific and Industrial Research would tend to discourage the research associations from undertaking these larger researches into problems not, at first sight, promising immediate benefits to the industry. When the industry has to find all the money for co-operative research, there will naturally be a tendency on the part of the industry to concentrate more and more on research work deemed likely to bring immediate or early benefits to the industry, and to postpone to a never-coming to-morrow those wider investigations which might not seem to promise results of immediate industrial value. It is because the continued association of the Government with the research associations helps the research associations to develop to the fullest extent all the capacities of co-operative research-because, shortly, the co-operative research is not fully co-operative without the co-operation of the Department of Scientific and Industrial Research - that the policy of putting a definite term to grants in aid is, in the national interest, mistaken.

Io. The Advisory Council in its report to the Committee of the Privy Council for the year 1916-17 (Cd. 87I 8 , p. I6) stated that there seemed to be room in the industrial world for three methods of financing research. "There is research which the individual firm finds it remunerative to undertake at its own expense. Secondly, there is research which is financed on a co-operative basis; and lastly, there is research which must be financed by the State if it is to be done at all." I submit that, in the national interest, the phrase "financed on a co-operative basis " should be interpreted as including the continuous financial co-operation of the State.

I do not pretend in this paper to have done more than to have touched lightly a few of the points that must arise in a discussion of this important matter. I hope, however, that I have said enough to show that the principle of limiting State aid to research associations to a definite and comparatively short term of years is neither axiomatic nor sacrosanct, but, judged from the national interest, and even by that criterion alone, of dubious value.

\title{
Sir Charles Parsons and the Steam Turbine.
}

$T^{H}$

HE presentation of the Kelvin Medal to Sir Charles Parsons, and the delivery of the James Forrest Lecture on "Radio Communications" by Senator Marconi, took place on October 26 at the Institution of Civil Engineers. The assembly was the largest ever seen at the Institution ; and among those present was the Italian Ambassador. In presenting the medal on behalf of the Kelvin Medal Award Committee, Sir William Ellis, the president of the Institution, referred to the work of Sir Charles Parsons in the fields of scientific inquiry and the applications of thermodynamics, remarking that the medal commemorated the achievements of Lord Kelvin in those branches of science which are especially applicable to engineering. Reference was made to the scientific environment in which Sir Charles Parsons was brought up and to the work of his father, the Earl of Rosse, who in 1845 completed the famous reflecting telescope at Birr Castle, and later Sir William Ellis sketched the progress of the steam turbine with which the name of Sir Charles Parsons is so closely associated.

The acknowledgment of the gift of the medal by Sir Charles Parsons was followed by some reminiscences of great interest. $\mathrm{He}$ touched upon his boyish attempts to construct models of such materials as were available - a far better thing for a boy than playing with mechanical toys. One of his early inventions was a sounding machine with a glass tube closed at the end, somewhat similar to that of Lord Kelvin, but, said Sir Charles humorously, "I believe Kelvin's invention was made independently." Sir Charles also reminded his hearers of his experiments in making diamonds, which, however, when tested, proved not to be diamonds at all. He still thought something might be done in that direction. When engaged with the steam turbine, the financial and commercial difficulties were greater than the scientific and mechanical, and he recalled with pleasure the favourable opinion of the turbine expressed by Lord Kelvin on more than one occasion. It was a notable day in the history of the turbine when the turboalternator set supplied to Cambridge in $\mathrm{I} 892$ showed an economy superior to the reciprocating engines of that time.

Sir Charles Parsons was born on June 15, I854, being the fourth son of the third Earl of Rosse. A glimpse of his early surroundings can be obtained from the "Reminiscences" of Sir Robert Ball, who in 1865 became tutor to Sir Charles and his two brothers. After being privately educated he entered St. John's College, Cambridge, and graduated in I 876, being eleventh wrangler. Four years were then spent at the famous Elswick Works, where he came under the influence of Lord Armstrong, and in I 883 he became junior partner in the firm of Clarke; Chapman, Parsons and Co., of Gateshead, where he began his life's work on the steam turbine.

Many patents for rotary engines were taken out during the nineteenth century, but modern turbine work begins with those of 1884 . First came the patent of the Swedish engineer, Gustav de Laval, for an impulso turbine, and this was followed by those of young Sir Charles Parsons. Of the patents of April 23, I 884, No. 6734 was for "improvements in electric generation and in working them by fluid pressure," and No. 6735 was for "improvements in rotary motors actuated by elastic fluid pressure, and applicable also as pumps."

The pioneer Parsons turbine constructed was a double-ended parallel-flow machine, running at 18 , ooo revolutions per minute, driving an armature only $2 \frac{5}{8}$ inches in diameter. This little machine was used in the Inventions Exhibition of $\mathbf{1} 885$, and is now at the Science Museum, South Kensington. By I889, 300 turbo-generators had been constructed, the largest being 75 kilowatts. Soon after this the firm of C. A. Parsons and Co. was founded, followed a few 
years later by the Parsons Marine Steam Turbine Co The year I887 saw the construction of the first compound turbine; the year I 892 that of the first condensing turbine. From the 75 -kilowatt set of 1889 the turbine gradually grew in size, sets of 3000 kilowatts being made in 1902, while to-day there are machines in use of 60,000 kilowatts. The development of the marine turbine is represented by the engines of H.M.S. Hood, of more than 150,000 horse power. The first turbine-driven vessel was the Turbinia, and this was followed by the destroyers H.M.S.'s Cobra and Viper, the cruiser Amethyst and the battleship Dreadnought, and other vessels for commercial purposes.
The work of Sir Charles Parsons during the last forty years has often received acknowledgment. He has been a fellow of the Royal Society since I 898 , and is an honorary doctor of science of six universities. From the Royal Society of Arts he has received the Albert Medal; from the Institution of Electrical Engineers, the Faraday Medal; and from the Franklin Institute of America, the Franklin Medal. In connexion with the award of the last, it was remarked that " it is no exaggeration to say that the work of Sir Charles Parsons has halved the cost of producing electric power, and reduced in stilı greater proportion the capital cost of generatin. machinery.'

\section{The Magnetic Storm and Aurora of October I4-I5, and Associated Solar Activity.}

THE magnetic storm which was recorded in NATURE of October 23, p. 603, was accompanied by a display of the aurora which, owing to cloudy skies over a large part of Great Britain, was not seen generally. It is therefore of added interest that Mr. W. B. Housman, of Seaton, West Cumberland, was able to secure eight photographs of the phenomenon, four of which are reproduced herewith (Fig. I).

It will be recalled that at Greenwich the commencement of a magnetic disturbance of moderate intensity was recorded on October I4 at 20 hr. This disturbance, which lasted for about i 2 hours, was followed on October $\mathrm{I}_{5}$ at I9 hr. by another of considerable magnitude, the magnetograph traces showing a total displacement of more than $I^{\circ}$ in declination. The two upper photographs of the aurora were taken at $\mathrm{I} h$. $30 \mathrm{~m}$. on October I 5 during the precursory disturbance, and the lower photographs show the aurora on the evening of the same day at $22 \mathrm{hr}$., that is, about three hours after the commencement of the major disturbance. The photographs were taken with a camera with an aperture of 2 in. and focal length of 4 in., the exposures being from Io to 15 minutes. In the upper photographs, taken with the camera pointed to left and right respectively of the centre of the auroral light, the constellation Lyra is seen on the left, and on the right the brilliancy of the aurora practically absorbs all the star trails, while the Scotch coast, 20 miles distant, is revealed by the light. The two lower views show the western extremity and the north-eastern region of the aurora on the following evening. Some details of the photographs are of course lost in reproduction.

Mr. Housman's remarks on the phenomenon may be quoted in full: "In all views taken, and particularly in these four, dark bands are to be seen running concentric with the auroral arc of light. They were noted visually, and are even more pronounced photographically, their position and persistent continuance suggesting a connexion with the aurora itself. The colours seen in this display were very beautiful. On October I 4, 23 h. 30 m., G.M.T., the arch frequently shone with a rich crimson glow, and on October I5, about 22 hr. G.M.T., the N.E. end was quite a bright green. Orange and pale straw colour
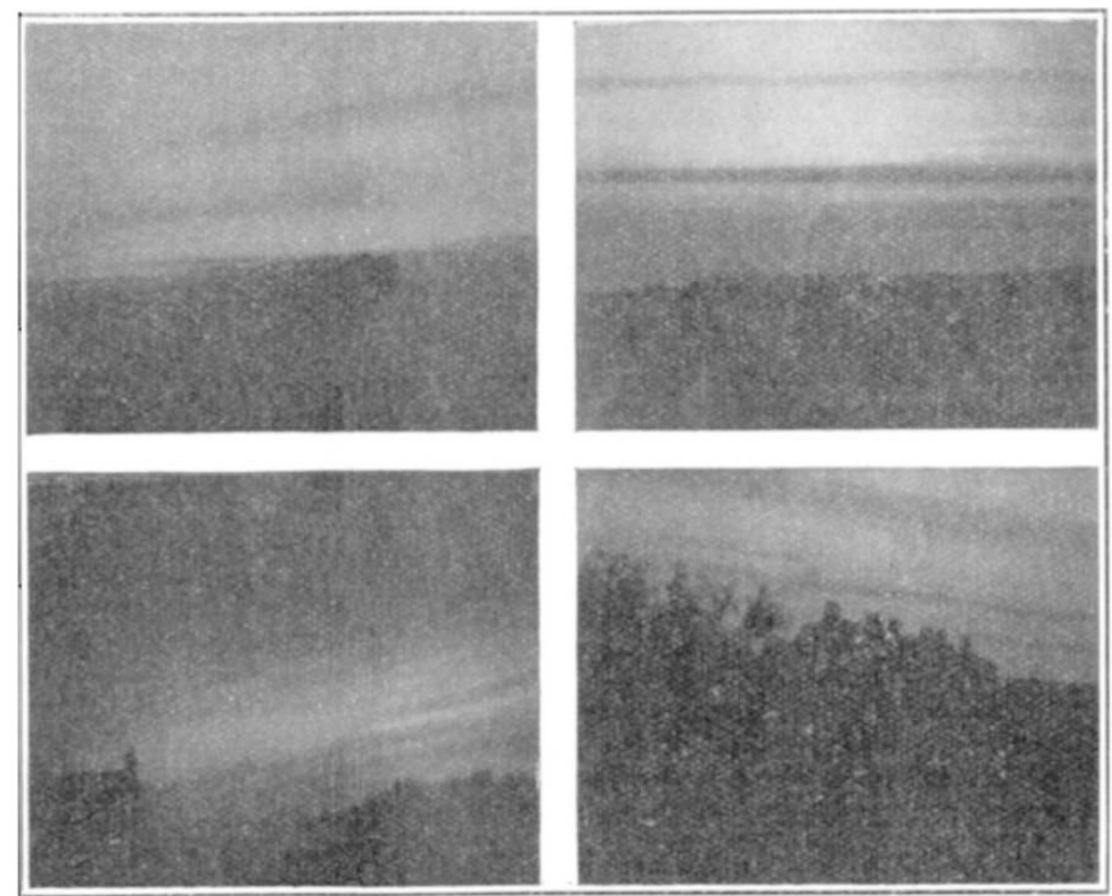

October I4-I5, 1926. From photographs by Mr. W. B. Housman.

also appeared in the arch at different places simultaneously. On the night of October I 5-I6 the auroral green line was seen in a pocket spectroscope all over the sky except in the south-east, where moonlight was strong for a time."

It is known that there is a definite tendency for auroræ, as well as magnetic storms, to occur at inturvals of about 27 days -the same interval in which the spot producing zones of the sun make one rotation as seen from the earth. Mr. Housman mentions that the recent aurora is apparently a return of a fine display seen on September $I_{5}$; a recurrence of the phenomenon should therefore be looked for about November II. Mr. Evershed in a letter to NATURE of December 29, I92I, p. 566, describes a sequence of disturbances lasting for six months, the mean period being 27.3 days. It is perhaps of interest to mention that at the time when the magnetic storm was most intense there were

$$
\text { NO. 2975, VOL. I I } 8 \text { ] }
$$

